
thoracic and thoracoabdominal aortic aneurysms. J Thorac Cardiovasc Surg. midterm out aortic rupture compared with open surgery. J Thorac Cardiovasc Surg. 2021;161: 2004-12.

\section{Commentary: Use it or lose it}

\author{
Kenji Minatoya, MD, PhD
}

The advent of thoracic endovascular aortic repair (TEVAR) has completely changed the therapeutic algorithm for thoracic aortic diseases. The benefits of TEVAR are less invasiveness and the rapidity of the procedure. These features are especially helpful in emergent settings. TEVAR could control lethal bleeding rapidly and save the life of the patient in a catastrophic situation.

In this issue of the Journal, Ogawa and colleagues ${ }^{1}$ report endovascular repair of nontraumatic descending thoracic aortic rupture (DTAR). The majority of the patients were treated by open surgery before 2005 and with TEVAR after 2015. Therefore, an accurate comparison between open repair and TEVAR may be difficult. Further, the longterm fate of the lesion treated with TEVAR is unknown due to a rather short follow-up period after TEVAR.

Yet, the surgical outcomes reported by Ogawa and colleagues with TEVAR for nontraumatic DTAR should be congratulated. Perhaps the excellent outcomes can be attributed to their superb techniques, but also to their fine teamwork. A previous report describing endovascular repair of DTAR by Jonker and colleagues ${ }^{2}$ indicated $15.2 \%$ hospital mortality rate with TEVAR, which is comparable with the current report. Jonker and colleagues ${ }^{2}$ stressed the high stroke rate $(7.6 \%)$ in their report. However, the rate of stroke with TEVAR in the article of Ogawa and colleagues was only $3.8 \%$. In my opinion, this fact indicates that more accumulated know-how of TEVAR for DTAR has improved the outcome.

\footnotetext{
From the Department of Cardiovascular Surgery, Graduate School of Medicine, Kyoto University, Kyoto, Japan.

Disclosures: Author has nothing to disclose with regard to commercial support.

Received for publication Nov 21, 2019; revisions received Nov 21, 2019; accepted for publication Nov 21, 2019; available ahead of print Dec 12, 2019.

Address for reprints: Kenji Minatoya, MD, PhD, 54 Kawarharacho, Shogoin,

Sakyo-ku, Kyoto, 6068507 Japan (E-mail: minatoya@kuhp.kyoto-u.ac.jp).

J Thorac Cardiovasc Surg 2021;161:2014-5

0022-5223/\$36.00

Copyright (c) 2019 by The American Association for Thoracic Surgery

https://doi.org/10.1016/j.jtcvs.2019.11.099
}

\section{5;150:814-21.}

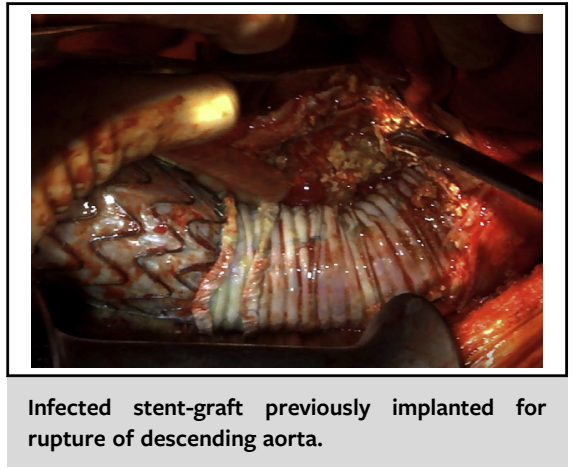

CENTRAL MESSAGE

TEVAR is undoubtedly an excellent procedure to save patients with DTAR; however, we should not cling to a binary choice and should not make a choice only between TEVAR and open surgery.

The study population included 13 aortobronchial fistula (ABFs) or aortoesophageal fistulas. The authors did not describe the procedures of the treatments and the following results minutely; however, TEVAR for $\mathrm{ABF}$ is associated with a high risk of recurrence of $\mathrm{ABF}^{3}$ Accordingly, TEVAR should be used as a bridge to definitive open repair. Bridging TEVAR to open surgery is also a useful adjunct in patients with aortoesophageal fistula with hemorrhagic shock. ${ }^{4}$ The authors described that there was a trend toward increased early and unplanned aortic reintervention in the TEVAR group. The rate of the reintervention was about $20 \%$, and there were several reasons for the reintervention. Yet, the mortality rate in patients requiring unplanned aortic reintervention was $50 \%$. In this point of view, I think early open conversion could be one of the options when initial hemostasis was obtained with TEVAR as the bridge in patients with DTAR.

Although the title of this report indicates the descending aortic rupture, the enrolled population included 12 patients 
with thoracoabdominal aortic aneurysms. TEVAR has been broadly applied to thoracic aortic diseases, but it is more easily applied at the aorta without major branches. TEVAR for thoracoabdominal aortic aneurysm requires additional procedures for the branches. In fact, 4 such cases were treated with TEVAR, and all 3 survivors had chimney/snorkel stent in abdominal branch vessels. Although this kind of high-tech strategy may be a future direction of aortic repair, the long-term results with the new technologies are still obscure, and open conversion from this complicated approach is often difficult.

TEVAR is undoubtedly an excellent procedure to save the patients with DTAR; however, we should not cling to a binary choice and should not make a choice only between
TEVAR and open surgery. In my opinion, these 2 major strategies should be combined properly for patients.

\section{References}

1. Ogawa Y, Watkins AC, Lingala B, Nathan I, Chiu P, Iwakoshi S, et al. Improved midterm outcomes after endovascular repair of nontraumatic descending thoracic aortic rupture compared with open surgery. J Thorac Cardiovasc Surg. 2021;161: 2004-12.

2. Jonker FH, Verhagen HJ, Lin PH, Heijmen RH, Trimarchi S, Lee WA, et al. Open surgery versus endovascular repair of ruptured thoracic aortic aneurysms. $J$ Vasc Surg. 2011;53:1210-6.

3. Canaud L, Alric P, Gandet T, Albat B, Marty-Ané C, Berthet JP. Surgical conversion after thoracic endovascular aortic repair. J Thorac Cardiovasc Surg. 2011; 142:1027-31.

4. Yamazato T, Nakamura T, Abe N, Yokawa K, Ikeno Y, Koda Y, et al. Surgical strat egy for the treatment of aortoesophageal fistula. J Thorac Cardiovasc Surg. 2018; 155:32-40.
See Article page 2004 .

\section{Commentary: The moment of truth: Longer-term follow-up after endovascular treatment of descending thoracic aortic rupture}

\author{
Meghana R. K. Helder, MD
}

Routinely in practice, there is a patient who asks, "Do you still really have to cut me open to fix this?" And the affirmative answer to this question is often couched in questions of the durability of the minimally invasive option. The one place in cardiac surgery that we have moved toward the minimally invasive option being the standard of care is repair of the descending thoracic aorta, especially in times of rupture. The data are quite clear that short-term outcomes are better when these patients are approached with thoracic endovascular aortic repair (TEVAR) instead of open repair. ${ }^{1}$ However, the questions that still remain unanswered are

From the Department of Cardiovascular Surgery, North Central Heart Institute, Sioux Falls, SD.

Disclosures: Author has nothing to disclose with regard to commercial support.

Received for publication Nov 25, 2019; revisions received Nov 25, 2019; accepted for publication Nov 28, 2019; available ahead of print Dec 14, 2019.

Address for reprints: Meghana R. K. Helder, MD, North Central Heart Institute, 4520 W 69th St, Sioux Falls, SD 57108 (E-mail: MHelder@ncheart.com).

J Thorac Cardiovasc Surg 2021;161:2015-6

$0022-5223 / \$ 36.00$

Copyright (C) 2019 by The American Association for Thoracic Surgery

https://doi.org/10.1016/j.jtcvs.2019.11.113

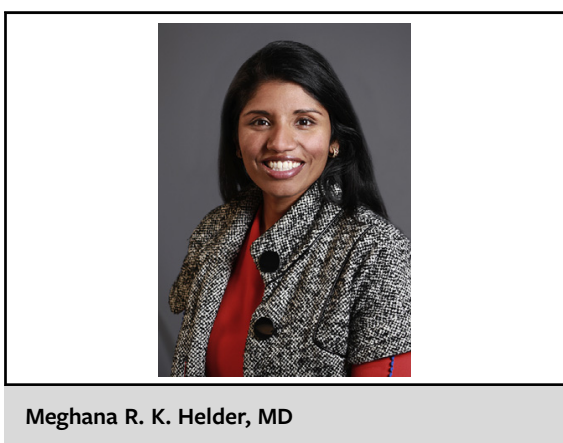

CENTRAL MESSAGE

Patients undergoing TEVAR for

descending thoracic aortic

rupture have a $70 \%$ 5-year sur-

vival rate as compared with $44 \%$

in patients undergoing open

surgical repair.

whether TEVAR is durable and what is the price to the patient with aortic reintervention.

Ogawa and colleagues ${ }^{2}$ must be congratulated in asking the important question of what are the mid-term outcomes of patients who underwent TEVAR for aortic rupture. This study does not include patients with traumatic rupture, which does carry a sicker patient cohort; however, it does limit the generalizability of the paper. The authors have a meaningful average follow-up of $828 \pm 1258$ days for 